\title{
Pengaruh kampung KB pada intervensi gizi sensitif stunting di Desa Janegara
}

\author{
Vilda Ana Veria Setyawati*, Faizzatun Ramadha
}

\begin{abstract}
Background: Stunting in Brebes, Central Java is the highest 100 in Indonesia. Through the Family Plan Village (Kampung KB), National Population and Family Planning Board (BKKBN) was given the mandate to contribute in accelerating the improvement of nutrition, especially the problem of stunting. 15,873 villages in Indonesia were formed as Kampung KB. However, there were no studies that describe the extent to which the program was effective.

Objectives: This study aims to determine the effectiveness of the Kampung KB on sensitive intervention to prevent stunting.

Methods: Experimental research with and one group only post test study design used. In 60 mothers of children under the age of 24 months starting in March-October 2019 in Janegara Village, Brebes Regency. The intervention carried out was the Kampung KB. Its activities at the study site are conducted from March-October 2019 in the study population's parents. The intervention was family counseling by family planning counselors (PKB). The variables measured included planning for household life, habituation of clean and healthy lifestyles in the family, empowering family at home, and responsive care. Data was collected using a questionnaire that was prepared independently and has been tested for validity and reliability. Analysis of the data used to prove the hypothesis is one sample t test.

Results: Most of the mothers understand family life planning (75\%), PHBS practices are appropriate (61.37\%), the role of fathers is good (83.3\%), and mothers have taken responsive care responsive care (55\%). Kampung KB is effective for improving the practice of PHBS $(p=0.003)$ and the role of fathers in the family $(p=0.0001)$.

Conclusion: Kampung KB was effective to increase (PHBS) and the role of fathers in parenting.
\end{abstract}

Keywords : kampung KB; stunting; sensitive intervention

\section{ABSTRAK}

Latar Belakang : Angka stunting di Kabupaten Brebes, Jawa Tengah merupakan 100 besar tertinggi di Indonesia. Melalui Kampung KB, BKKBN diberikan amanat untuk berkontribusi dalam mempercepat perbaikan gizi, khususnya masalah stunting. 15.873 desa di Indonesia dibentuk sebagai Kampung KB. Akan tetapi belum ada penelitian yang memaparkan sejauh mana programnya efektif.

Tujuan : Penelitian ini bertujuan untuk mengetahui efektivitas kampung stunting pada upaya sensitif pencegahan stunting.

Metode: Penelitian ini merupakan penelitian eksperimen kuasi dengan pendekatan kuantitatif dan desain one group only post test studi. Pada 60 ibu anak berusia di bawah 24 bulan mulai bulan Maret-Oktober 2019 di Desa Janegara Kabupaten Brebes. Intervensi yang dilakukan yaitu kampung KB. Kegiatannya di lokasi penelitian dilakukan mulai bulan Maret-Oktober 2019 pada orang tua populasi penelitian. Intervensinya berupa konseling oleh penyuluh keluarga berencana (PKB). Variabel yang diukur meliputi perencanaan hidup berumah tangga, pembiasaan pola hidup bersih dan sehat pada keluarga, pemberdayaan keluarga serumah, dan pengasuhan responsive. Data diambil dengan menggunakan kuesioner yang disusun mandiri dan sudah diuji validitas dan reliabilitasnya. Analisis data yang dipakai untuk membuktikan hipotesis adalah one sample t test.

Hasil : Sebagian besar ibu memahami perencanaan hidup berumah tangga (75\%), praktek PBHS sudah sesuai (61,37\%), peran ayah sudah baik (83,3\%), serta ibu sudah menjalankan pengasuhan tanggap responsive dengan baik (55\%). Kampung KB efektif untuk perbaikan praktek PHBS $(p=0,003)$ dan peran ayah dalam keluarga $(p=0,0001)$.

Simpulan : Kampung KB efektif untuk memperbaiki pada praktek pola hidup bersih sehat (PHBS) dan peran ayah dalam pengasuhan anak.

Kata Kunci : kampung KB; stunting; upaya sensitif.

\section{PENDAHULUAN}

Stunting menjadi salah satu dari isu masalah kesehatan yang ditangani pemerintah Republik Indonesia RI secara serius sejak tahun 2018. Prevalensi di atas $20 \%$ dari tahun ke tahun menjadi dasar kuat untuk segera ditanggulangi karena hal ini menentukkan kualitas bangsa ke depannya. Target WHO di tahun 2025, menekan angka stunting turun 40\% dari jumlah yang terhitung tahun 2012. ${ }^{1}$ Angka stunting di Kabupaten Brebes, Jawa Tengah merupakan 100 besar tertinggi di Indonesia, sehingga menjadi alasan bahwa untuk menjadi kabupaten prioritas dalam penanganan stunting. ${ }^{2}$ Riset Kesehatan Dasar, pada 2013, angka

Departemen Kesehatan Masyarakat, Fakultas Kesehatan, Universitas Dian Nuswantoro. J1. Nakula I No. 5-11, Semarang, Jawa Tengah 50131, Indonesia

*Korespondensi : e-mail: vilda.setyawati@dsn.dinus.ac.id 
stunting di Brebes masih mencapai 43,6 persen dari jumlah penduduk. Sedangkan berdasarkan Pemantauan Status Gizi (PSG) usia 0-59 bulan, pada 2016, angka stunting 21,7. Kemudian 2017 sebesar 28,5 persen, dan 2018 sebesar 28,7 persen. ${ }^{3}$

Upaya-upaya penanganan dan pencegahan stunting yang selama ini dilakukan melalui puskesmas dan posyandu antara lain dengan pemberian vitamin A, pemenuhan gizi untuk ibu hamil hingga melahirkan, pemberian makanan tambahan anak, hingga pemantauan tumbuh kembang anak.Penanganan stunting melibatkan banyak pihak, tidak hanya dari kesehatan tetapi juga dari BKKBN, Kominfo, dan lembaga-lembaga swadaya masyarakat. ${ }^{4}$

Survei awal pada beberapa masyarakat dari berbagai umur menunjukkan bahwa pemahamannya tentang stunting belum tepat. Pemahaman mendasar yang masih salah adalah diagnosis stunting yang sebenarnya dari TB menurut umur, bukan menurut berat badan. Anak yang sudah terlanjur stunting akan sulit ditangani, karena pertambahan tinggi tidak sama dengan berat badan. Sehingga upaya yang sebaiknya dilakukan akan mencegah terjadinya stunting.

Terkait dengan arah kebijakan pembangunan nasional pemerintah tahun 2015-2019, BKKBN diberi mandat untuk mensukseskan Agenda Pembangunan Nasional (Nawacita), khususnya Agenda Prioritas ke-3 "Membangun Indonesia dari Pinggiran dengan Memperkuat Daerah-daerah dan Desa dalam rangka Negara Kesatuan", Agenda Prioritas ke-5 "Meningkatkan Kualitas Hidup Manusia Indonesia", serta Agenda Prioritas ke-8 "Revolusi Karakter Bangsa" melalui Pembangunan Kependudukan dan Keluarga Berencana. Amanat Presiden RI kepada BKKBN agar dapat menyusun suatu kegiatan/program yang dapat memperkuat upaya pencapaian target/sasaran Pembangunan Bidang Pengendalian Penduduk dan Keluarga Berencana 2015-2019, kegiatan tersebut dapat menjadi ikon BKKBN serta dapat secara langsung bersentuhan dan memberikan manfaat kepada masyarakat Indonesia di seluruh tingkatan wilayah. ${ }^{5}$ Dalam hal ini kemudian disepakati agar BKKBN segera membentuk Kampung Keluarga Berencana (Kampung $\mathrm{KB})$.

Melalui Kampung KB, BKKBN diberikan amanat untuk berkontribusi dalam mempercepat perbaikan gizi, khususnya masalah stunting. Melalui edaran sekretaris utama nomor 2/SE.SES/B1/2019 tentang pelaksanaan kegiatan dana bantuan operasional keluarga berencana tahun anggaran 2019, terkait dengan program ini program kampung $\mathrm{KB}$ juga dibentuk dengan prioritas pada desa terpapar stunting. Desa Janegara di Kecamatan Jatibarang Kabupatan Brebes merupakan pilot project pembentukan kampung $\mathrm{KB}$ di desa yang terpapar masalah stunting. Kampung KB merupakan program yang diluncurkan oleh pemerintah Indonesia yang ditujukan untuk pemberdayaan dan meningkatkan kondisi kesejahteraan desa dengan sosial ekonomi bawah sejak tahun 2016 .

Intervensi masalah stunting sendiri meliputi dua kelompok besar yaitu upaya spesifik dan upaya sensitif. Upaya spesifik merupakan penanganan stunting dari sektor kesehatan yang ditujukan kepada anak dalam 1000 hari pertama kehidupan (HPK) yang pada umumnya dilakukan pada sektor kesehatan. Sifat intervensi ini jangka pendek. Misalnya pemberian makanan tambahan untuk ibu hamil dengan kekurangan energi kronik (KEK), ASI eksklusif, vitamin A, obat cacing dan lainnya. Sedangkan upaya intervensi sensitif adalah intervensi yang ditujukan melalui berbagai kegiatan pembangunan pada umumnya di luar sektor kesehatan dengan sasaran masyarakat umum dan bersifat jangka panjang. ${ }^{4}$

Upaya pembentukkan kampung KB untuk mencegah stunting sudah dilaksanakan di beberapa daerah di Indonesia, dengan mengutamakan daerah yang masuk prioritas. Jumlah terkirini meliputi 15.845 desa sebagai Kampung KB. Akan tetapi belum ada penelitian yang memaparkan sejauh mana programnya efektif.

Program-program kegiatan kampung KB yang sudah disosialisikan melalui website resmi bkkbn.go.id memiliki sasaran yang sama dengan program penurunan stunting. Perbedaannya, kampung KB menekankan pada 8 fungsi keluarga yang diharapkan dapat mencegah stunting. Dengan kata lain, kampung KB tidak langsung berdampak pada balita stunting tetapi justru ke upaya sensitif dalam menurunkan stunting.l Penelitian ini bertujuan untuk mengetahui efektivitas kampung stunting pada upaya sensitif pencegahan stunting yang meliputi perencanaan hidup berumah tangga, pembiasaan pola hidup bersih dan sehat pada keluarga, pemberdayaan keluarga serumah, dan pengasuhan responsif.

\section{BAHAN DAN METODE}

Penelitian ini merupakan penelitian eksperimen kuasi menggunakan pendekatan kuantitatif dengan desain one group only post test study. Waktu penelitian dilakukan selama Maret-Oktober 2019.

Populasi penelitian ini adalah 60 ibu balita berusia dibawah 24 bulan di desa Janegara Kecamatan Jatibarang Kabupaten Brebes. Sampel diambil dengan teknik total sampling pada seluruh dengan kriteria balita di bawah 24 bulan. Kriteria inklusi yaitu balita berusia $\leq 24$ bulan yang berada di wilayah desa Janegara. Pertimbangan ini diambil karena mereka masih dalam masa 1000 hari pertama kehidupan (HPK). Kriteria eksklusi yaitu balita meninggal atau pindah rumah selama penelitian berlangsung.

Tidak ada kelompok perlakukan dan hanya diukur setelah perlakukan. Intervensi yang dilakukan yaitu 
kampung KB. Kegiatannya di lokasi penelitian dilakukan mulai bulan Maret-Oktober 2019 pada orang tua populasi penelitian. Intervensinya berupa konseling oleh penyuluh keluarga berencana (PKB). Konseling ini dilakukan bersamaan saat posyandu berlangsung selama kurun waktu di tahun 2018 pada meja konsultasi kesehatan. Indikator keberhasilan dilihat pada beberapa aspek yang dimasukkan sebagai variabel terikat, yaitu upaya sensitif mencegah stunting yang meliputi perencanaan hidup berumah tangga (mean=8,42), pembiasaan pola hidup bersih dan sehat pada keluarga (mean=9.17), pemberdayaan keluarga serumah $($ mean $=8,13)$, dan pengasuhan responsif $($ mean $=8.43)$. Data diambil dengan menggunakan kuesioner tertutup yang disusun mandiri dan sudah diuji validitas dan reliabilitasnya. Masing-masing variabel terdiri dari 10 pertanyaan berupa benar dan salah. Setiap responden memiliki 4 nilai dari masing-masing variabel terikat. Responden memiliki 4 skor yang dikategorikan baik jika $\geq$ mean dan kurang jika <mean. Analisis data yang dipakai untuk membuktikan hipotesis adalah one sample t test.

\section{HASIL}

Distribusi karakteristik responden yang terlibat sebagai berikut (Tabel 1).

Tabel 1. Profil Ibu Berdasarkan Umur, Pendidikan, Pekerjaan, dan Paritas

\begin{tabular}{|c|c|c|c|}
\hline \multicolumn{2}{|c|}{ Variabel } & $\mathbf{n}$ & $\%$ \\
\hline \multicolumn{4}{|c|}{ Umur } \\
\hline - & $<20$ tahun & 1 & $1,7 \%$ \\
\hline & $20-35$ tahun & 39 & $65 \%$ \\
\hline- & $>35$ tahun & 20 & $33,3 \%$ \\
\hline \multicolumn{4}{|c|}{ Pendidikan } \\
\hline- & Tidak tamat SD & 2 & $3,3 \%$ \\
\hline- & $\mathrm{SD}$ & 13 & $21,7 \%$ \\
\hline- & SMP & 21 & $35 \%$ \\
\hline- & SMA & 21 & $35 \%$ \\
\hline- & Perguruan tinggi & 3 & $5 \%$ \\
\hline \multicolumn{4}{|c|}{ Pekerjaan } \\
\hline- & Ibu rumah tangga & 54 & $90 \%$ \\
\hline- & Swasta & 4 & $6,7 \%$ \\
\hline- & Wiraswasta & 2 & $3,3 \%$ \\
\hline \multicolumn{4}{|c|}{ Paritas } \\
\hline- & Primipara & 24 & $40 \%$ \\
\hline- & Multipara & 36 & $60 \%$ \\
\hline
\end{tabular}

Tabel 2. Distribusi Perencanaan Hidup Berumahtangga

\begin{tabular}{lcc}
\hline Pernyataan & Benar & Salah \\
\hline $\begin{array}{l}\text { Usia cukup untuk menikah antara 20-30 tahun dengan pertimbangan } \\
\text { kematangan organ reproduksi dan tingkat emosional }\end{array}$ & $54(90 \%)$ & $6(10 \%)$ \\
\hline $\begin{array}{l}\text { Perencanaan jarak kelahiran anak mempengaruhi proses pengasuhan } \\
\text { untuk mencapai pertumbuhan dan perkembangan anak }\end{array}$ & $48(80 \%)$ & $12(20 \%)$ \\
\hline Usia 35 tahun ke atas, berisiko tinggi untuk menjadi ibu hamil & $35(58,3 \%)$ & $25(41,7 \%)$ \\
\hline $\begin{array}{l}\text { Dalam fungsi perlindungan, orang tua harus menumbuhkan rasa } \\
\text { aman, nyaman, dan hangat bagi seluruh anggota keluarga sehingga } \\
\text { anak-anak merasa aman }\end{array}$ & $58(96,7 \%)$ & $2(3,3 \%)$ \\
\hline $\begin{array}{l}\text { Dampak teknologi tidak bisa dipungkiri berpengaruh pada } \\
\text { pertumbuhan dan perkembangan anak sehingga penggunaannya } \\
\text { dibatasi saat di depan anak }\end{array}$ & $58(96,7 \%)$ & $2(3,3 \%)$ \\
\hline
\end{tabular}

Tabel 3. Praktek Pola Hidup Bersih dan Sehat

\begin{tabular}{lcc}
\hline Pertanyaan & Ya & Tidak \\
\hline Percaya persalinan hanya pada tenaga kesehatan & $55(91,7 \%)$ & $5(8,3 \%)$ \\
\hline Bayi berusia 0-6 bulan hanya mendapatkan ASI saja & $46(76,7 \%)$ & $14(23,3 \%)$ \\
\hline $\begin{array}{l}\text { Ibu rutin untuk memantau hasil penimbangan berat badan balita } \\
\text { minimal 1 bulan sekali }\end{array}$ & $49(81,7 \%)$ & $11(18,3 \%)$ \\
\hline Rumah tangga hanya menggunakan air bersih & $56(93,3 \%)$ & $4(6,7 \%)$ \\
\hline $\begin{array}{l}\text { Seluruh anggota dalam keluarga memiliki kebiasaan mencuci } \\
\text { tangan dengan sabun, terutama saat dari luar atau sebelum makan }\end{array}$ & $53(88,3 \%)$ & $7(8,3 \%)$ \\
\hline Rumah tangga memiliki atau menggunakan jamban sehat & $55(91,67 \%)$ & $5(8,33 \%)$ \\
\hline $\begin{array}{l}\text { Rutin melakukan pemberantasan sarang nyamuk dengan 3 M } \\
\text { plus }\end{array}$ & $52(86,67 \% 0$ & $8(13,33 \%)$ \\
\hline $\begin{array}{l}\text { Anggota rumah tangga rutin mengkonsumsi sayur dan buah } \\
\text { untuk memenuhi kebutuhan serat }\end{array}$ & $52(86,67 \% 0$ & $8(13,33 \%)$ \\
\hline Seluruh anggota keluarga rutin melakukan aktifitas fisik & $57(95 \%)$ & $3(5 \%)$ \\
\hline Ada anggota keluarga yang merokok & $30(50 \%)$ & $30(50 \%)$ \\
\hline
\end{tabular}


Tabel 4. Peran Ayah Dalam Keluarga

\begin{tabular}{lcc}
\hline Pertanyaan & Ya & Tidak \\
\hline $\begin{array}{l}\text { Ayah memiliki tanggung jawab dalam mendukung ibu } \\
\text { melewati proses perslainan }\end{array}$ & $1(1,7 \%)$ & $59(98,3 \%)$ \\
\hline Ayah memberikan respon pada anak jika dia menangis & $2(33 \%)$ & $58(96,7 \%)$ \\
\hline Bayi dan balita perlu mendapat perhatian dari ayah & $3(5 \%)$ & $57(96,7 \%)$ \\
\hline Ayah perlu berinteraksi dengan bayi/balita & $4(6,7 \%)$ & $56(93,3 \%)$ \\
\hline Ayah perlu mengajak bayi/balita bermain bersama & $3(5 \%)$ & $57(95 \%)$ \\
\hline Anak menjadi merupakan tanggung jawab bersama & $3(5 \%)$ & $57(95 \%)$ \\
\hline
\end{tabular}

Tabel 5. Kategori Upaya Pencegahan Stunting

\begin{tabular}{lcc}
\hline Variabel & n (\%) & $\begin{array}{c}\text { Binomial } \\
\text { Test }\end{array}$ \\
\hline Perencanaan hidup berkeluarga & & 0,092 \\
- Kurang Paham & $23(38,3 \%)$ & \\
- Paham & $37(61,7 \%)$ & \\
Praktek PHBS & & $0,003^{*}$ \\
- Kurang sesuai & $18(30 \%)$ & \\
- Sesuai & $42(70 \%)$ & \\
Peran ayah & $10,0001^{*}$ \\
- Kurang & $(16,67 \%)$ & \\
- Baik & 50 & \\
$\quad$ & $(83,33 \%)$ & \\
Pengasuhan tanggap responsive & $27(45 \%)$ & 0,519 \\
- Kurang & $33(55 \%)$ & \\
- Baik & & \\
\hline
\end{tabular}

Tabel 1 menunjukkan sebagian besar ibu berada pada usia produktif dan tidak berisiko (65\%). Ibu berpendidikan $35 \%$ tamat SMP dan SMA, hanya sebagian kecil saja yang lulus di pegruruan tinggi (5\%). Anak-anak di kampung KB ini diasuh sebagian besar oleh ibu rumah tangga (90\%). Dan tabel ini juga menunjukkan sebagian besar ibu memiliki anak 2 atau lebih $(60 \%)$.

Pada tabel 2 menunjukkan pernyataan yang terkait dengan perencanaan hidup berkeluarga, dimana sebagian besar sudah menunjukkan jawaban yang benar. Artinya, sebagian besar ibu di Desa Janegara sudah memahami poin-poin penting untuk membangun kehidupan berumah tangga.

Tabel 3 menunjukkan 10 komponen perilaku hidup bersih dan sehat, dimana sebagian besar sudah dipraktekan. Namun, pada pernyataan adanya perokok dalam keluarga, 50\% keluarga ibu perokok dan tidak perokok.

Tabel 4 menunjukkan persepsi ibu pada peran ayah terhadap anak. Sebagian besar sudah dilakukan sesuai dengan semestinya. Seperti ayah yang wajib mencari nafkah $(68,3 \%)$, ayah merasa punya kewajiban mengasuh anak $(68,3 \%)$, ayah memiliki tanggung jawab dalam mendukung ibu melahirkan $(98,3 \%)$, ayah mengetahui jam menyusui anak (85\%), Namun, pada beberapa pernyataan, menurut ibu, ayah belum memberikan peran sesuai dengan seharusnya. Misalnya, ayah tidak memberikan respon saat anak menangis
(96,7\%), bayi dan blita tidak perlu mendapat perhatian dari ayah $(96,7 \%)$, ayah perlu berinteraksi dengan bayi/balita $(93,3 \%)$, sesekali ayah harus menggendong bayi $(91,7 \%)$, ayah mengajak balita bermain bersama (95\%), dan anak merupakan tanggung jawab bersama (95\%).

Upaya sensitif dalam mencegah stunting dikategorikan menjadi 2 sesuai dengan tabel 5 di atas. Sebagian besar ibu memahami perencanaan hidup berumah tangga $(75 \%)$, praktek PBHS sudah sesuai $(61,37 \%)$, peran ayah sudah baik $(83,3 \%)$, serta ibu sudah menjalankan pengasuhan tanggap responsive dengan baik (55\%). PHBS dan peran ayah menunjukan efektif dengan adanya kampung KB. Dari ke empat variabel yang diukur, kampung $\mathrm{KB}$ efektif untuk perbaikan praktek PHBS $(\mathrm{p}=0,003)$ dan peran ayah dalam keluarga $(\mathrm{p}=0,0001)$.

\section{PEMBAHASAN}

Pembentukan 8 fungsi keluarga yakni fungsi keagamaan, fungsi sosial budaya, fungsi cinta kasih, fungsi perlindungan, fungsi reproduksi, fungsi sosial dan pendidikan, fungsi ekonomi serta fungsi lingkungan belum tercapai pada seluruh wilayah Indonesia. Delapan fungsi keluarga tersebut merupakan cerminan dari kesejahteraan dan ketahanan keluarga. Kampung KB dibentuk sejak tahun 2016, bertujuan untuk pelaksanaan pembentukan keluarga berencana dengan melakukan pemberdayaan masyarakat. Berdasarkan pada tujuan pembentukkannya di awal, program ini tidak untuk mengatasi stunting. Seiring dengan meluasnya masalah stunting, upaya sensitif memiliki peran yang besar meskipun tidak berdampak langsung. Upaya sensitif tersebut membutuhkan peran keluarga yang cukup besar, sehingga kampung $\mathrm{KB}$ juga memasukkan program kerjanya untuk ikut berperan mengatasi stunting dengan penguatan peran keluarga. Stunting perlu diatasi dengan dukungan keluarga, sehingga pendekatan melalui kampung KB penting untuk tercapai target programnya. ${ }^{6}$ Kampung KB merupakan perwujudan dari sinergi antara beberapa kementerian terkait dari pemerintah pusat dan pemerintah daerah, mitra kerja, dan pemangku kepentingan, serta tidak ketinggalan partisipasi langsung masyarakat setempat. Oleh sebab itu Kampung KB ini diharapkan menjadi miniatur atau gambaran (potret) dari 
sebuah desa yang didalamnya terdapat keterpaduan dari program pembangunan Kependudukan, KB dan Pembangunan Keluarga yang disinergikan dengan program pembangunan sektor terkait yang dilaksanakan secara sistemik dan sistematis. ${ }^{7}$

Masalah gizi stunting merupakan dampak dari berbagai aspek kesehatan dan non kesehatan yang berjalan tidak sesuai dengan seharusnya. Sejak tahun 2018, pemerintah Indonesia gencar menggerakkan berbagai program untuk menangainya. Sejatinya, stunting bisa dicegah tetapi jika sudah mengalami, intervensi dilakukan tidak bisa dengan mudah membuahkan hasil. Stunting tidak hanya membuat seseorang terlihat pendek, tetapi selama pertumbuhan badan terhambat, pertumbuhan otak dan fisiologis lain juga mengalami proses yang sama, sehingga stunting memberikan dampak masa depan yang cukup fatal bagi seorang anak. ${ }^{2}$ Penelitian yang dilakukan pada remaja yang terkumpul melalui Indonesian Life Survey (ILS) dari tahun 1993-2007 menunjukkan bahwa anak stunting berisiko 3,4 kali menjadi remaja obesitas dibandingkan anak dengan tinggi badan normal. ${ }^{8}$

Sampai saat ini tercatat sudah ada 15.747 kampung KB di Indonesia di portal resmi BKKBN. Desa Janegara menjadi salah satu diantaranya. Pemangku kebijakan Kampung KB di Desa Janegara menerbitkan sudat edaran untuk menangani stunting pada keluarga dari perencanaan hidup keluarga, praktek PHBS, peran ayah, dan pengasuhan tanggap responsif.

Anak yang berada pada keluarga berencana memiliki risiko stunting lebih rendah dibandingkan dengan anak yang berada pada keluarga dengan jumlah anggota lebih besar. Ini merupakan hasil penelitian bersumber pada data Riset Kesehatan Dasar 2013 yang diolah dan menunjukkan hasil bahwa risiko stunting meningkat dengan meningkatnya anggota rumah tangga $(\mathrm{AOR}=1,03 ; 95 \%$ CI: $1,02-1,04) .{ }^{9}$

Berdasarkan hasil penelitian, kampung KB efektif dalam melakukan intervensi pada praktek PHBS dan peran ayah $(p<0,05)$. Sebagian besar praktek PHBS dan peran ayah sudah sesuai dengan poin-poin yang diharapkan pada pelaksanaan kampung KB. Penelitian ini sejalan dengan pelaksanaan kampung $\mathrm{KB}$ di wilayah Denpasar pada keluarga miskin, dimana keberadaan kampung KB efektif untuk meningkatkan kesejahteraan keluarga secara ekonomi. ${ }^{10}$ Hasil penelitian ini juga sejalan dengan penelitian yang dilakukan pada balita stunting di Palembang, dimana pola asuh yang didalamnya termasuk pengasuhan ayah dan kebiasaan kebersihan $(\mathrm{p}<0,05)$, secara statistik berhubungan dengan kejadian stunting. ${ }^{11}$

Pada perencanaan hidup berkeluarga dan pengasuhan tanggap responsif, kampung $\mathrm{KB}$ secara statistik tidak efektif dalam kedua intervensi tersebut ( $>0,05)$. Akan tetapi jika dilihat skoringnya, sebagian besar ibu sudah paham perencanaan hidup berkeluarga
(75\%) dan dari persepsi ibu dan melakukan pengasuhan tanggap responsif pada anak-anaknya (55\%). Pemahaman hidup berkeluarga merupakan pengetahuan umum yang bisa didapatkan dari sumber-sumber informasi di sosial media dan pengalaman kedua orang tuanya. Sehingga belum tentu didapatkan dari keberadaan kampung KB. Begitupula dengan pengasuhan tanggap responsif. Bahkan orang tua jaman dahulu, dapat mengasuh anaknya dengan baik tanpa adanya media memperoleh informasi. Pola asuh yang baik bisa didapatkan dari pola asuh orang tua sebelumnya dan lingkungan. Sejalan dengan penelitian yang dilakukan pada kampung KB di Jawa timur. Keberadaan kampung KB di Jawa Timur masih butuh dukungan banyak pihak agar bisa mencapai tujuan. Sejauh ini, adanya kampung KB disana efektif dalam peningkatan frekuensi Komunikasi, Informasi, dan Edukasi (KIE) oleh Petugas Lapangan Keluarga Berencana (PLKB) di masyarakat. Belum ada dampak khusus pada kehidupan masyarakat. ${ }^{12}$

Intervensi gizi sensitif juga telah dilakukan di banyak wilayah. Penelitian di Bogor menunjukkan intervensi gizi sensitif dilakukan pada kesehatan lingkungan yang meliputi adanya jumat bersih dalam rangka meningkatkan kualitas praktek PHBS bersama dasa wisma, pengumpulan bank sampah, perbaikan drainase dan sanitasi berbasis lingkungan (STBM). Selain itu juga dilakukan intervensi pada pemberdayaan perempuan dengan bentuk kegiatan konseling dengan berbagai topik yang dijadwal dengan tujuan untuk menanamkan pemahaman pada ibu akan pentingnya peran wanita dalam sebuah keluarga. Peraturan presiden RI No.42 Tahun 2013 yang dikutip oleh Rosha BC dkk menyatakan bahwa intervensi gizi sensitif diyakini berkontribusi sebesar $70 \%$ dalam mengatasi permasalahan gizi. Hal ini mendukung keberdaan kampung KB dalam mencegah stunting sebagai upaya intervensi sensitif penanganan stunting. ${ }^{13}$

Berdasarkan data yang dihimpun UNICEF, penanganan stunting di Brazil dikaitkan dengan meningkatkan status sosial ekonomi keluarga dengan peningkatan penghasilan, penyediaan air bersih dan stunting melalui upaya sensitif. Hal itu berupa pemberian dana secara tunai dan program perlindungan soal anak, dan pengembangan kapasitas sosial. Perlindungan anak dan pengembangan kapasitas sosial memberikan hasil positif dalam mengurangi kurang gizi di wilayah tersebut. Akan tetapi perlu dikaji untuk pemberian bantuan dana tunai apakah benar untuk membeli keperluan anak atau tidak. Intervensi berupa pengembangan kapasitas sosial, isinya sejalan dengan penanaman perencanaan hidup berkeluarga yang dilakukan kampung KB. ${ }^{14}$ Sehingga penelitian di Nepal ini sangat mendukung hasil yang diperoleh dari keberadaan kampung KB di Desa Jenegara. 
Kondisi prevalensi stunting Indonesia hampir sama dengan India, dimana India menunjukkan sebesar $38 \% .{ }^{15}$ Intervensinya juga dilaukan disana secara merata, karena stunting merupakan masalah gizi yang kompleks dengan dampak jangka panjang yang ditanggung oleh penderita dan masyarat nasional. Kebersihan individu yang diupayakan tercapai melalui PHBS mendukung upaya penurunan stunting. Badan yang bersih memiliki imunitas yang lebih baik sehingga risiko mengalami diare dan penyakit infeksi lain akan lebih rendah. Infeksi berpengaruh langsung terhadap terjadinya masalah gizi, termasuk stunting. ${ }^{16}$

Seperti yang sudah dikatakan sebelumnya, penelitian ini merupakan penelitian eksperimen dengan pendekatan satu kelompok tanpa kontrol dan juga pre test. Akan tetapi hal ini dilakukan karena intervensi kampung KB tidak bisa dibandingkan dengan wilayah yang bukan kampung KB. Dan sebelum program dilaksanakan, tidak ada data terkait variabel yang diukur sebagai pre test. Ke depan akan dilakukan penelitian lebih lanjut untuk efektivitas kampung KB pada aspek yang lain.

\section{SIMPULAN}

Kampung KB mendukung untuk upaya intervensi stunting dari aspek sensitif. Penelitian ini membuktikan adanya efektivitas tersebut pada praktek pola hidup bersih sehat (PHBS) dan peran ayah dalam pengasuhan anak. Kedua variabel lain tidak terbukti efektif tetapi perlu diperhatikan, bahwa sebagian besar komponen perencanaan hidup berumah tangga dan pengasuhan tanggap responsif menunjukkan hasil yang baik.

\section{DAFTAR PUSTAKA}

1. WHO. Reducing stunting in children. Equity considerations for achieving the Global Nutrition Targets 2025. 2018.

2. Kementerian PPN/ Bappenas. Pedoman Pelaksanaan Intervensi Penurunan Stunting Terintegrasi di Kabupaten/Kota. Rencana Aksi Nas dalam Rangka Penurunan Stunting Rembuk Stunting. 2018

3. Pusat Data dan Informasi Kemenkes RI. Situasi Balita Pendek (Stunting) di Indonesia. Buletin Jendela Data dan Informasi Kesehatan. 2018;53(9):1689-99.

4. Bappenas. Pedoman Pelaksanaan Intervensi Penurunan Stunting Terintegrasi di Kabupaten/ Kota. Rencana Aksi Nasional dalam Rangka Penurunan Stunting: Rembuk Stunting. 2018.

5. Kementerian Kesehatan RI. Kampung KB : Inovasi Strategis Memberdayakan Masyarakat. 19 Maret. 2018.
6. Tentama F, Delfores HDL, Wicaksono AE, Fatonah SF. Penguatan Keluarga Sebagai Upaya Menekan Angka Stunting Dalam Program Kependudukan, Keluarga Berencana Dan Pembangunan Keluarga (Kkbpk). Jurnal Pemberdaya Publikasi Hasil Pengabdian Kepada Masyarakat. 2018;2(1):113.

7. Badan Kependudukan dan Keluarga Berencana Nasional. Petunjuk Teknis Kampung KB Tahun 2015. Badan Kependudukan dan Keluarga Berencana Nasional. 2015;53(9):1689-99.

8. Simbolon D. Model Prediksi Indeks Massa Tubuh Remaja Berdasarkan Riwayat Lahir dan Status Gizi Anak. Kesmas: National Public Health Journal. 2013;8(1):19.

9. Wicaksono F, Harsanti T. Determinants of Stunted Children in Indonesia: A Multilevel Analysis at the Individual, Household, and Community Levels. Kesmas: National Public Health Journal. 2020;15(1):48.

10. Restiyani NLN, Murjana Yasa IGW. Efektivitas Program Kampung Keluarga Berencana (Kb) Dan Dampaknya Terhadap Kesejahteraan Keluarga Miskin Di Kota Denpasar. E-Jurnal Ekon dan Bisnis Universitas Udayana. 2019;7:711.

11. Bella FD, Fajar NA. Jurnal Gizi Indonesia Hubungan pola asuh dengan kejadian stunting balita dari keluarga miskin di Kota Palembang. Jurnal Gizi Indonesia (the Indonesian Journal of Nutrition). 2019;8(1):31-9.

12. Mardiyono. Kampung KB Sebagai Upaya Pemberdayaan Masyarakat/ Keluarga di Jawa Timur (Studi di Kota Malang dan Kabupaten Bondowoso). Jurnal Cakrawala. 2017;11(2):12936. Available from: http://cakrawalajournal.org/index.php/cakrawala/ar ticle/viewFile/13/13

13. Rosha BC, Sari K, SP IY, Amaliah N, Utami NH. Peran Intervensi Gizi Spesifik dan Sensitif dalam Perbaikan Masalah Gizi Balita di Kota Bogor. Buletin Penelitian Kesehatan. 2016;44(2):127-38.

14. Renzaho AMN, Chitekw S, Chen W, Rijal S, Dhakal T, Dahal P. The synergetic effect of cash transfers for families, child sensitive social protection programs, and capacity building for effective social protection on children's nutritional status in Nepal. Int J Environ Res Public Health. 2017;14(12).

15. Aguayo VM, Menon P. Stop stunting: Improving child feeding, women's nutrition and household sanitation in South Asia. Matern Child Nutr. 2016;12:3-11.

16. Cumming O, Cairncross S. Can water, sanitation and hygiene help eliminate stunting? Current evidence and policy implications. Matern Child Nutr. 2016;12:91--05. 